PAPER

\title{
A double blind, randomised study of sildenafil citrate for erectile dysfunction in men with multiple sclerosis
}

\author{
C J Fowler, J R Miller, M K Sharief, I F Hussain, V J Stecher, M Sweeney*
}

J Neurol Neurosurg Psychiatry 2005;76:700-705. doi: 10.1136/jnnp.2004.038695

See end of article for authors' affiliations

.......................

Correspondence to:

Clare J Fowler,

Department of'Uro-

Neurology, The National

Hospital for Neurology

and Neurosurgery,

Mailbox 71, Queen

Square, London WCIN

3BG, UK; cfowler@ion.ucl. ac.uk

Received 5 February 2004 In revised form

18 August 2004

Accepted 18 August 2004
Objective: Identifying and effectively treating erectile dysfunction (ED) can result in an improvement of the quality of life (QoL) in men with multiple sclerosis (MS).

Methods: This randomised, double blind (DB), placebo controlled, flexible dose study with an open label extension (OLE) assessed efficacy, QoL, and safety of sildenafil citrate in men with MS and ED. Overall, 217 men received sildenafil $(25-100 \mathrm{mg} ; n=104)$ or placebo $(n=113)$ for 12 weeks. Efficacy was assessed by the International Index of Erectile Function (IIEF) questionnaire that includes questions on achieving (Q3) and maintaining (Q4) an erection as well as a global efficacy question (GEQ). QoL was also assessed.

Results: After 12 weeks, patients receiving sildenafil had higher mean scores for IIEF Q3 and Q4 compared with those receiving placebo $(p<0.0001)$, and $89 \%(92 / 103)$ reported improved erections compared with $24 \%(27 / 112)$ of patients receiving placebo $(p<0.0001)$. At the end of the OLE phase, $95 \%$ of men reported improved erections. Patients receiving placebo during the DB phase showed a nearly fourfold increase in improved erections (97\% v 26\%). Men receiving sildenafil also showed improvements in five of the eight general QoL questions compared with men receiving placebo $(p<0.05)$. The total mean score for the QoL questionnaire improved by $43 \%$ for the sildenafil group versus $13 \%$ for the placebo group $(p<0.0001)$. Treatment related AEs were predominantly mild in nature, and no patient discontinued due to an $\mathrm{AE}$.

Conclusion: Sildenafil treatment for ED in men with MS was effective and well tolerated, and resulted in significant improvements in both general and disease specific QoL variables.
S exual dysfunction and especially erectile dysfunction (ED) is a common problem for men with multiple sclerosis (MS). ${ }^{1-4}$ Although several reports have now shown the incidence of ED in men with MS to be $50 \%{ }^{45}$ to $75 \%,{ }^{5}$ the frequency of the problem and its impact on the patient's quality of life (QoL) have been underestimated in the past.

Sexual dysfunction is likely to occur at a time when the patient with MS is beginning to experience impaired mobility and other disabilities that interfere with aspects of social and occupational life, and it is thus likely to contribute to the depression and difficulties that accompany a progressively disabling disease. The dyadic relationship is particularly important in a disease in which one partner has to adjust to increasing physical dependency on the other, and restoration of erectile function may be of great significance to both partners. Therefore, identifying and effectively managing ED may result in an improvement in the QoL of patients with MS. ${ }^{7-9}$

Formerly, ED in MS patients was thought to have a major psychological component, probably because under certain circumstances erections are preserved; however, it has since become clear that ED in patients with MS is commonly associated with neurogenic bladder dysfunction ${ }^{35}$ and that both disorders are the result of spinal cord involvement. ${ }^{3} 10$ Generally, with the onset of ED, men with MS continue to experience nocturnal erections or erections in response to genital stimulation, but these are often not sufficiently sustained for intercourse.

Sildenafil citrate is an effective and well tolerated treatment for ED of diverse causes, ${ }^{11}{ }^{12}$ including spinal cord injury (SCI). ${ }^{14}$ Sildenafil has a peripheral site of action ${ }^{15}$ and enhances erectile function only after sexual stimulation. ${ }^{16}$ This randomised, placebo controlled study evaluated the efficacy and safety of sildenafil in men with ED and concomitant MS in addition to evaluating changes in their QoL following sildenafil treatment.

\section{METHODS}

\section{Patients}

The inclusion criteria for enrolment required that men be at least 18 years of age with a documented diagnosis of ED of greater than 6 months duration and be in a stable relationship with a woman for at least 6 months. Patients were also required to have a diagnosis by a neurologist of clinically definite MS of at least 1 year's duration, based on standard clinical or investigational criteria; however, an omission not recognised at the time of this study was that no information on the type of MS was collected. In addition, patients were required to have a stable residual disability level of 2 to 6 inclusive on the Kurtzke Extended Disability Status Scale (EDSS), that is, they were ambulatory patients. ${ }^{17}$ All patients provided written informed consent.

Men were excluded from enrolment if they had genital anatomical deformities that significantly impaired erections or major haematological, renal, or hepatic abnormalities. Other exclusion criteria were the coexistence of other sexual disorders considered to be the primary diagnosis, an uncontrolled major psychiatric disorder, or significant cardiovascular disease (stroke or myocardial infarction within the previous 6 months; sitting blood pressure $<90 / 50 \mathrm{~mm} \mathrm{Hg}$ or $>180 / 110 \mathrm{~mm} \mathrm{Hg}$ ). Patients with a known history of retinitis pigmentosa or who were taking nitrates, nitric oxide donors,

Abbreviations: $A E$, adverse event; $D B$, double blind; $E D$, erectile dysfunction; EDSS, Extended Disability Status Scale; GEQ, global efficacy question; IIEF, International Index of Erectile Function; MS, multiple sclerosis; OLE, open label extension; QoL, quality of life; $\mathrm{SCl}$, spinal cord injury 
or who had used corticosteroids for the treatment of MS within the previous 2 months were not allowed to enter the study. Termination of other medications or therapies for ED was required.

\section{Protocol and participant flow}

This study was conducted between 1997 and 1999 at 20 sites (11 in the United States and nine in Europe) and had a 16 week, randomised, double blind (DB), placebo controlled, flexible dose design (fig 1). It was outpatient based and had a 4 week run in phase (week -4 to week 0 ), during which time baseline data on sexual function were collected. This was followed by a 12 week DB phase of treatment with sildenafil or placebo (week 0 to week 12). The $50 \mathrm{mg}$ starting dose of sildenafil or matching placebo could be adjusted to 100 or $25 \mathrm{mg}$ based on therapeutic response and tolerability. Patients were instructed to take sildenafil or placebo as required approximately $\mathrm{l} \mathrm{h}$ before sexual activity, with a maximum dosing frequency of once daily. The DB treatment period was followed by an open label extension (OLE) phase. Men who had completed the DB phase or who had discontinued treatment due to lack of efficacy or nontreatment related adverse events (AEs) and for whom there were no safety or compliance concerns were eligible to enter the OLE phase, which lasted a minimum of 24 weeks up to a maximum of 48 weeks or until sildenafil became commercially available in the study country, whichever occurred first. Because the initial blind was not broken until completion of both phases of the study, patients entering the OLE phase started with the $50 \mathrm{mg}$ dose, irrespective of the last dose taken during the DB phase.

\section{Randomisation and blinding}

A randomisation list was generated using random permuted blocks through a computer algorithm and a pseudorandom number generator. The list indicated, for each bottle number, the drug assigned to the corresponding study medication bottle. The patient was assigned a screening number at visit one (screening) and, if eligible for participation, was then assigned a randomisation number at visit two (baseline). The investigator was provided a sealed copy of the randomisation codes and was instructed to break the treatment code only in the event of an emergency. Active treatment and corresponding placebo tablets were identical in packaging and appearance.

\section{Efficacy and safety assessments}

During the DB phase, the primary efficacy variables were responses to questions "When you attempted sexual intercourse, how often were you able to penetrate your partner?" (Q3) and "When you attempted sexual intercourse, how often were you able to maintain your erection after you had penetrated your partner?" (Q4) of the 15 item International Index of Erectile Function (IIEF). The IIEF is a validated questionnaire that has been used for the clinical assessment of ED. ${ }^{18}$ Each question of the IIEF is scored on a categorical scale of 1 ("almost never/never") to 5 ("almost always/ always"), with a score of 0 indicating "did not attempt sexual intercourse". Secondary efficacy variables were responses to three global efficacy questions (GEQs): GEQ1: “Compared to having no treatment at all for your erection problem, has the medication you have been taking over the past 4 weeks improved your erections?" and GEQ2: "If yes, has the

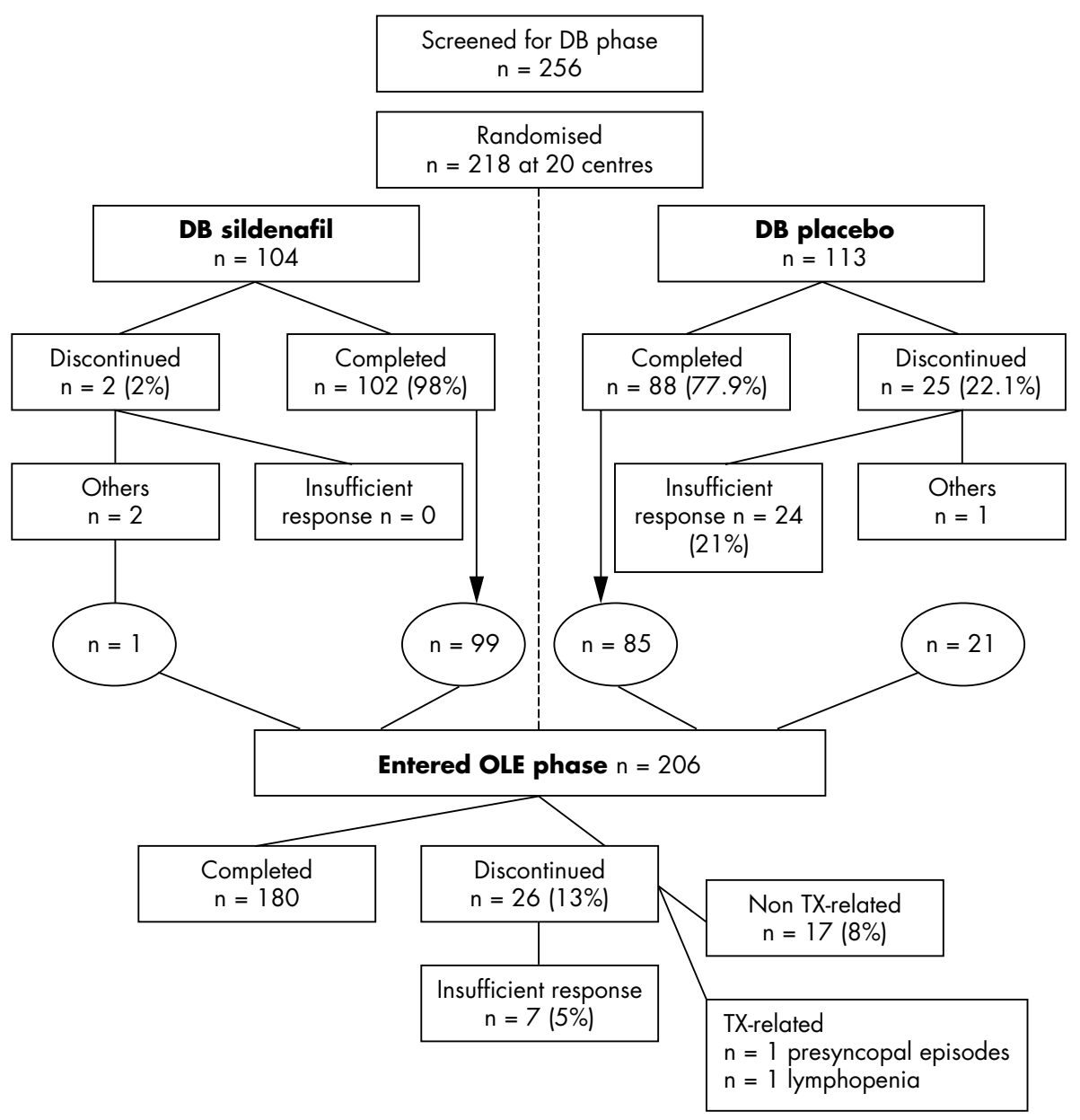

Figure 1 Progress of patients through the DB and OLE phases of the study. $\mathrm{DB}$, double blind; OLE, open label extension; TX, treatment. 
improvement in your erections allowed you to engage in satisfactory sexual activity?". GEQ3 asked: "When you took a dose of study drug and had sexual stimulation, how often did you get an erection that allowed you to engage in satisfactory sexual activity?". GEQ3 was scored the same as the IIEF.

Additional secondary efficacy measures were analyses of IIEF domains, for example, orgasmic function (Q9: “When you had sexual stimulation or intercourse, how often did you ejaculate?" and Q10: "When you had sexual stimulation or intercourse, how often did you have the feeling of orgasm?") and sexual desire (Q11: "Over the past 4 weeks, how often have you felt sexual desire?" and Q12: "Over the past 4 weeks, how would you rate your level of sexual desire?"). AEs were recorded throughout the study. The DB end point efficacy assessment served as baseline for the OLE phase. At the final OLE visit, a limited assessment of efficacy was made based on responses to the three GEQs.

\section{Quality of life assessments}

Two instruments were used to assess QoL. The Life Satisfaction Checklist is an eight item general QoL questionnaire, with questions on the patient's satisfaction with life as a whole, sexual life, partnership relation, family life, social contacts, and leisure, vocational, and financial situations. ${ }^{19}$ The Erection Distress Scale is a disease specific instrument with five questions on the patient's concerns with his erection problems. These were: "Were you frustrated about your erection problems?", "Did you feel weighed down by your erection problems?", "Were you discouraged by your erection problems?", "Did you feel despair over your erection problems?", and "Were your erection problems a worry in your life?". Responses to each question of the Life Satisfaction Checklist and the Erection Distress Scale were scored from 1 (none of the time) to 6 (all of the time).

\section{Analyses}

Calculations were performed to determine the sample size needed to detect a statistical difference in the mean end point response for sildenafil (combined 25, 50, and $100 \mathrm{mg}$ dose groups) versus placebo. Based upon a difference of 1.33 in mean scores and assuming a common standard deviation for sildenafil and placebo of 2.0, a sample size of 50 patients per treatment arm was sufficient to achieve a power of $90 \%$ to detect the specified difference between the two treatment groups using an approximation (two sided, $\alpha=0.05$ ) to the test comparing two means for normally distributed responses. Assuming an overall drop out rate of 25\%, a $1: 1$ randomisation ratio of sildenafil to placebo, sufficient power to be able to conduct the primary analysis of efficacy, analysis of covariance, including terms for treatment group, centre, baseline value for efficacy variables, and other covariates as required, 250 patients, 125 in each arm, were to be randomised to study drug; in total, 218 patients were randomised.

Intent-to-treat analyses were performed on all efficacy and QoL variables, and included all patients with at least one assessment after randomisation who had taken at least one dose of study drug. To be eligible for inclusion in safety analyses, patients must have taken at least one dose of study drug. Statistical analysis of responses to IIEF Q3 and Q4 and GEQ3 was performed for each question using analysis of covariance. Statistical analysis of responses to GEQ1 and GEQ2 (yes/no) was performed for each question using a logistic regression model.

The mean frequency of responses to each question of the Life Satisfaction Checklist and to the five questions of the Erection Distress Scale for each treatment was calculated and expressed as the least squares mean \pm standard error (SE). Each question was fitted with an analysis of covariance model, which included terms for treatment group, centre, patient age, baseline score, ED duration, baseline ED severity, and smoking status. All statistical tests were two sided and performed at the $5 \%$ significance level.

\section{RESULTS}

\section{Efficacy during the double blind phase}

A total of 217 men (mean age: 46 years; mean duration of ED: 5.7 years; mean duration of MS: 10.4 years) from 20 sites in the United States and Europe received treatment with sildenafil $(\mathrm{n}=104)$ or placebo $(\mathrm{n}=113)$ for 12 weeks. The patients in the two treatment groups had similar demographic characteristics with respect to age, duration of ED, duration of MS, and EDSS score (table 1), but men in the placebo group reported more frequent use of antihypertensive agents and less use of corticosteroids compared with the treatment group. At the end of the 12 week period, almost two thirds of men $(64 \%)$ receiving sildenafil were taking the $100 \mathrm{mg}$ dose, compared with $32 \%$ on the $50 \mathrm{mg}$ dose, and $4 \%$ on the $25 \mathrm{mg}$ dose. In the placebo group, $96 \%$ of men were taking the $100 \mathrm{mg}$ dose, and $4 \%$ were taking the $50 \mathrm{mg}$ dose.

The ability to achieve erections (IIEF Q3) and the ability to maintain erections (IIEF Q4) were improved in patients with MS who received sildenafil compared with those who received placebo $(\mathrm{p}<0.0001$; fig 2$)$. When questions from the IIEF were analysed by domain, men taking sildenafil demonstrated a greater than fivefold improvement in orgasmic function $(\mathrm{Q} 9,10 ; \mathrm{p}<0.0001)$ and greater than fourfold improvement in sexual desire (Q11, 12; $p=0.0002)$ from baseline, compared with patients receiving placebo (fig 3).

Improvements in erections (GEQ1) were reported by $90 \%$ (95\% CI: 82 to 94 ) of patients in the sildenafil group compared with $24 \%$ (95\% CI: 17 to 33 ) of those in the placebo group $(\mathrm{p}<0.0001$; fig 4$)$. In those patients with improved erections after sildenafil treatment (sildenafil responders), 92\% (95\% CI: 82 to 96 ) reported an improvement in the ability to have satisfactory sexual activity (GEQ2; fig 4). Patients taking sildenafil had a greater mean score for the frequency of erections that allowed satisfactory sexual activity (GEQ3, 4.0) compared with patients taking placebo (2.0; $\mathrm{p}<0.0001)$.

\begin{tabular}{|c|c|c|}
\hline & $\begin{array}{l}\text { Placebo } \\
(n=113)\end{array}$ & $\begin{array}{l}\text { Sildenafil } \\
(n=104)\end{array}$ \\
\hline Mean age (range), years & $47(23-65)$ & $45(26-73)$ \\
\hline Mean duration of ED & & \\
\hline (range), years & $(0.9-29.0)$ & $(0.7-23.1)$ \\
\hline Mean duration of MS & 10.1 & 10.7 \\
\hline (range), years & $(1.1-40.3)$ & $(1.5-46.4)$ \\
\hline Mean EDSS score (range) ${ }^{*}$ & $4.06(1.5-6)$ & $3.97(1-6)$ \\
\hline \multicolumn{3}{|l|}{ Concomitant medications, \%† } \\
\hline Analgesics & 16.8 & 21.2 \\
\hline Antibacterials & 13.3 & 13.5 \\
\hline Antidepressants & 21.2 & 17.3 \\
\hline Antiepileptics & 11.5 & 15.4 \\
\hline Antihypertensives & 20.4 & 12.5 \\
\hline Corticosteroids & 8.8 & 21.2 \\
\hline $\begin{array}{l}\text { Drugs affecting immune } \\
\text { response }\end{array}$ & 26.5 & 28.8 \\
\hline $\begin{array}{l}\text { Muscle relaxants/antispastic } \\
\text { agents }\end{array}$ & 27.4 & 29.8 \\
\hline Drugs for rheumatic diseases & 22.1 & 16.3 \\
\hline Vitamins & 19.5 & 15.4 \\
\hline
\end{tabular}

*EDSS (Extended Disability Status Scale) scores available for 89 men (placebo) and 83 men (sildenafil); tused by $>10 \%$ of patients. 


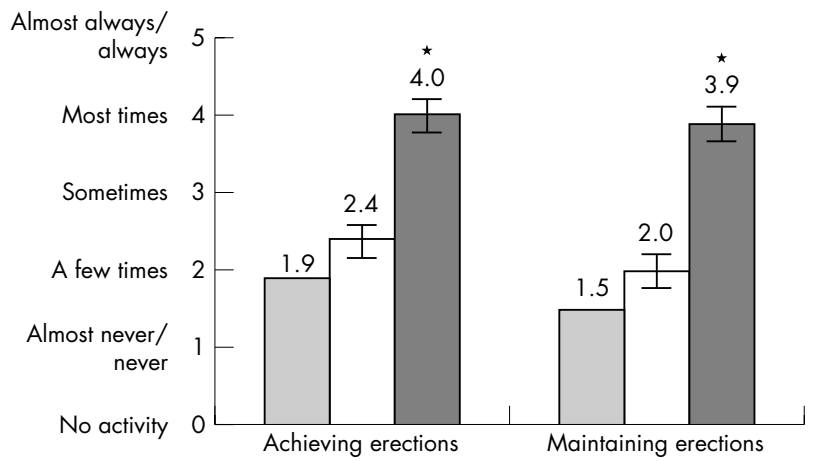

Figure 2 Mean scores ( \pm SE) for IIEF Q3 (achieving erections) and Q4 (maintaining erections) are shown at baseline (grey bars) and with placebo (white bars) and sildenafil use (black bars). ${ }^{*} p<0.0001$ versus placebo. IIEF, International Index of Erectile Function.

\section{Efficacy during the open label extension phase}

Overall, 206 men (placebo: $\mathrm{n}=106$; sildenafil: $\mathrm{n}=100$ ) entered and 180 patients completed the 48 week OLE phase. At the end of the OLE phase, efficacy of sildenafil was sustained, with $95 \%$ of men reporting improved erections as determined by GEQ1. Of those patients, 95\% also reported improved sexual activity (GEQ2). Patients who had received placebo during the DB phase showed a nearly fourfold increase in improved erections at the end of the OLE phase (97\% v 26\%). An improvement in the ability to have successful sexual activity (GEQ2) was reported by men from both the DB placebo (96\% $v 73 \%$ ) and the sildenafil groups (94\% v 89\%). However, because only patients who responded "yes" to GEQ1 were included here, these percentages are based on fewer patients from the DB placebo group $(\mathrm{n}=26)$ than from the sildenafil group $(\mathrm{n}=81)$ answering the GEQ2. At the end of the OLE phase, for patients who received DB placebo, the frequency of erections more than doubled (mean score: $4.35 v 1.98$ ) and was similar to the frequency observed in men who received DB sildenafil (mean score: 4.26).

\section{Quality of life}

At the end of treatment, men with ED and MS who received sildenafil showed significant improvements in five of the eight variables of the general QoL questionnaire (Life Satisfaction Checklist) compared with those who received placebo (fig 5). The QoL variables that demonstrated an improvement from baseline in patients receiving sildenafil

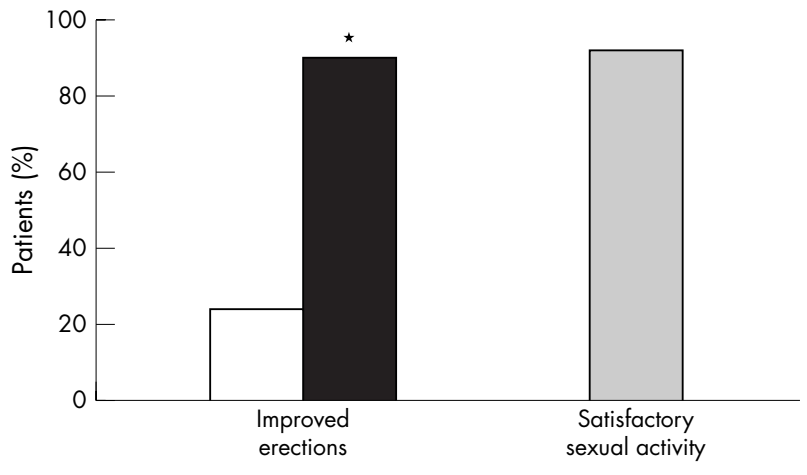

Figure 4 Percentage of patients reporting improvements in erections (GEQ1) with placebo (white bar) and sildenafil (black bar). The ability to have satisfactory sexual activity (GEQ2) is reported in those patients that responded to sildenafil (grey bar). Values represent estimated percentages calculated from logistic regression, adjusting for the model covariates. ${ }^{*} \mathrm{p}<0.0001$ versus placebo. GEQ, global efficacy question.

were satisfaction with life as a whole (13\% sildenafil $v 3.2 \%$ placebo; $p=0.001)$, sexual life $(86 \%$ sildenafil $v 22 \%$ placebo; $\mathrm{p}<0.001)$, partnership relation $(11 \%$ sildenafil $v 2.3 \%$ placebo; $\mathrm{p}=0.001)$, family life $(7.5 \%$ sildenafil $v 1.0 \%$ placebo; $\mathrm{p}=0.003)$, and social contacts $(3.5 \%$ sildenafil $v$ $-1.7 \%$ placebo; $p=0.03)$. The change in mean scores between the two treatment groups was not significantly different for satisfaction with leisure, vocational, or financial situation. The total mean score for the disease specific Erection Distress Scale increased 43\% from baseline for the sildenafil group compared with $13 \%$ for the placebo group $(\mathrm{p}<0.0001)$.

\section{Safety during the double blind phase}

The most common AEs related to the study drug, which were predominantly mild to moderate in nature, are listed in table 2. Serious AEs were reported by three patients in the sildenafil group (urinary tract infection, worsening MS, exacerbation of MS) and three patients in the placebo group (weakness (probable worsening of MS), bone disorder, myocardial infarction). None of these events were considered by the investigator to be related to treatment. A total of 102 patients $(98 \%)$ in the sildenafil group completed the study compared with 88 patients $(78 \%)$ in the placebo group (table 2). No patient in the sildenafil group discontinued treatment because of an AE.

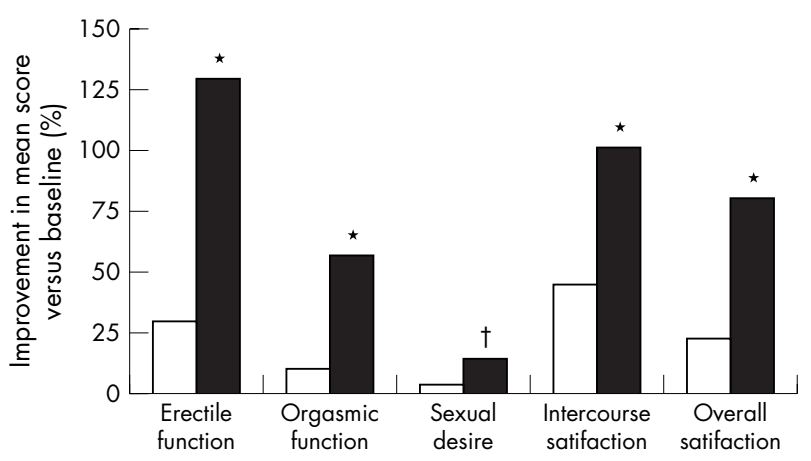

Figure 3 Improvements in the mean scores of two IIEF domains, orgasmic function and sexual desire, from baseline with placebo (white bars) or sildenafil treatment (black bars). ${ }^{*} p<0.0001 ; \uparrow p=0.0002$ versus placebo. IIEF, International Index of Erectile Function.

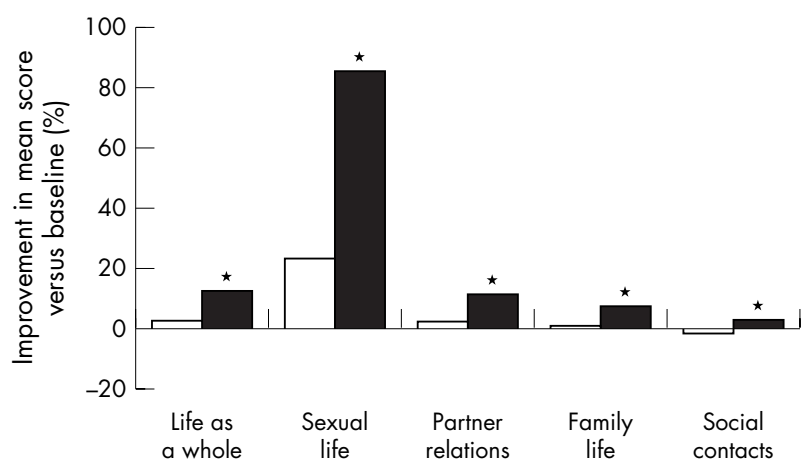

Figure 5 Quality of life variables that improved with sildenafil treatment (black bars) compared with placebo (white bars). ${ }^{*} \mathrm{p}<0.05$. 
Table 2 Treatment emergent AEs

\begin{tabular}{|c|c|c|c|}
\hline & \multicolumn{2}{|c|}{$\begin{array}{l}\text { DB phase, } \\
\% \text { of patients }\end{array}$} & \multirow{2}{*}{$\begin{array}{l}\text { OLE phase, } \\
\% \text { of patients } \\
\text { Sildenafil } \\
\text { (n=206) }\end{array}$} \\
\hline & $\begin{array}{l}\text { Placebo } \\
(n=113)\end{array}$ & $\begin{array}{l}\text { Sildenafil } \\
(\mathrm{n}=104)\end{array}$ & \\
\hline $\begin{array}{l}\text { Patients with AEs of all } \\
\text { causalities }\end{array}$ & 43.4 & 66.3 & 73 \\
\hline $\begin{array}{l}\text { Patients with treatment } \\
\text { related AEs }\end{array}$ & 6.2 & 42.3 & 41 \\
\hline Patients with serious $A E s$ & 2.7 & 2.9 & 6 \\
\hline Patients with severe $\mathrm{AEs}$ & 3.5 & 9.6 & 10 \\
\hline $\begin{array}{l}\text { Patients discontinued due } \\
\text { to } \mathrm{AEs}\end{array}$ & 0.9 & 0 & 2 \\
\hline \multicolumn{4}{|l|}{$\begin{array}{l}\text { Most common AEs, all } \\
\text { causality* (treatment related) }\end{array}$} \\
\hline Headache & $7(4)$ & $27(21)$ & $23(19)$ \\
\hline Flushing & $2(2)$ & $13(13)$ & $16(15)$ \\
\hline Weakness $†$ & $1(0)$ & $6(0)$ & $4(0)$ \\
\hline MS relapse & $2(0)$ & $7(0)$ & $10(0)$ \\
\hline Rhinitis & $1(0)$ & $6(4)$ & $7(2)$ \\
\hline Chromatopsia & 0 & $4(4)$ & $4(4)$ \\
\hline Dyspepsia & 0 & $6(3)$ & $6(4)$ \\
\hline
\end{tabular}

${ }^{*} \mathrm{AEs}$ occurring in $\geqslant 3 \%$ patients of either treatment group; †may include MS relapse not specified as such.

$A E$, adverse event; $D B$, double blind; MS, multiple sclerosis; OLE, open label extension.

\section{Safety during the open label extension phase}

Overall, 26/206 (13\%) subjects discontinued the OLE phase (fig 1), and of these $11 / 106(10 \%)$ were sildenafil naïve during the DB phase. Of the 26 subjects who discontinued, 17 $(8 \%)$ did so for reasons not related to treatment (AEs, $\mathrm{n}=3$; laboratory abnormalities, $\mathrm{n}=1$; lost to follow up, withdrawal of consent, other, $\mathrm{n}=14$ ). The most common AEs are shown in table 2, and were comparable in nature and rate of occurrence to AEs reported in the DB phase of the study. Overall, 12 patients $(6 \%)$ reported treatment emergent serious AEs during the OLE phase, most of which $(n=9)$ were relapses of MS or aggravation of MS symptoms, requiring hospitalisation. Seven subjects experiencing these relapses had received sildenafil during the DB phase of the study and two patients had received placebo. In all cases, the subject returned to the study and completed the OLE phase without further worsening of the MS symptoms. None of the serious AEs were attributed to the study medication.

\section{DISCUSSION}

Sildenafil significantly improved erectile function and the ability to engage in satisfactory sexual activity in men with ED due to MS. Treatment with sildenafil was well tolerated, with $98 \%$ of the patients completing the study. Furthermore, oral sildenafil treatment resulted in significant improvements in both general and disease specific QoL variables, and the treatment therefore represents an important advance in the management of ED in this group of patients.

Although men participating in this study were ambulatory, indicative of their relatively mild spinal cord involvement (Kurtzke EDSS <6.0), one would expect sildenafil to be effective in improving erectile function in patients with more advanced disease as well; this has been demonstrated in men with complete spinal cord transection. ${ }^{13}{ }^{14}$ Although the pharmacological mechanism of sildenafil is not expected to affect desire and orgasmic function, both domains showed improvement in this current study. These improvements are thought to happen secondary to improvements in erectile function, with men feeling good about their ability to resume sexual activity and sildenafil enabling them to sustain an erection until orgasm is achieved.

During the DB phase, AEs associated with sildenafil use occurred more frequently than in the placebo group, raising an issue about patients being unblinded and introducing bias when answering subjective questionnaires. However, this is a potential issue in many clinical trials and the incidence of AEs related to sildenafil treatment in this study was comparable to that in other trials, for example, in patients with diabetes, ${ }^{20}$ depression, ${ }^{21}$ or $\mathrm{SCI}^{22}$ (range, $31-40 \%$ ).

Efficacy of sildenafil is comparable in men with ED and concomitant MS (current study) or SCI. ${ }^{13}{ }^{14}$ The ability to achieve an erection (IIEF Q3) was improved 1.6-fold in MS patients and 1.8-fold in SCI patients, whereas the ability to maintain an erection (IIEF Q4) improved 1.9-fold in MS patients and 2.1-fold in SCI patients. From the GEQ, the percentage of MS patients reporting improved erections was $90 \%$ for sildenafil users compared with $24 \%$ for placebo users; the percentage of SCI patients reporting improved erections was $75 \%$ for sildenafil users compared with $7 \%$ of placebo users. These data demonstrate that patients with ED due to spinal disease respond well to treatment with sildenafil. The results are comparable to or better than a population of patients with ED of mixed etiology $(72-79 \%)^{23}$ and markedly higher than in patients with diabetes mellitus (48-72\%), ${ }^{24}$ whose poorly preserved vasculature might be the main reason for low efficacy. Interestingly, there appears to be a greater efficacy of sildenafil in patients with MS than in patients with diabetes, since $64 \%$ of men with MS preferred the $100 \mathrm{mg}$ dose, compared with $75 \%$ of men with diabetes choosing that dose. ${ }^{20} 24$

Moreover, greater efficacy in patients with MS may be due to the fact that sildenafil acts peripherally, and although pyschogenically driven erections are likely to have been impaired by spinal cord disease, reflexogenic responses, subserved by sacral segmental pathways, are still intact. The average age of patients in this study is relatively young and with healthy peripheral neurovasculature a good erectile response is obtained by reflex mechanisms and what psychogenic responsiveness remains available.

Sildenafil was well tolerated in this study, as the majority of AEs reported during both phases were mild to moderate in severity and non-serious. AEs were those known to be associated with the mechanism of action of sildenafil, such as headache, vasodilation, and dyspepsia.

\section{CONTRIBUTORS}

The following clinical investigators contributed to this study: Dr Hans Jacob Hansen, Århus, Denmark; Dr Andreo Larsen, Helsinki, Finland; Dr Ragnar Stien, Moelv, Norway; Dr Morten Andersen, Moelv, Norway; Dr Sten Fredrikson, Huddunge, Sweden; Professor Clare Fowler, London, UK; Dr Mohammed K. Sharief, London, UK; Dr Jackie Palace, London, UK; Dr Ronald Murray, Englewood, CO, USA; Dr Douglas Jeffery, Winston-Salem, NC, USA; Dr Michael Kaufman, Charlotte, NC, USA; Dr Mary Ann Picone, Teaneck, NJ, USA; Dr Iqbal Hussain, London, UK; Dr Andrew Goodman, Rochester, NY, USA; Dr Lawrence Jacobs, Buffalo, NY, USA; Dr Aaron Miller, Brooklyn, NY, USA; Dr James Miller, New York, NY, USA; Dr Robert Salant, New York, NY, USA.

\section{Authors' affiliations}

C J Fowler, Department of Uro-Neurology, The National Hospital for Neurology and Neurosurgery, Mailbox 71, Queen Square, London WCIN 3BG, UK

J R Miller, The Neurologic Institute, 710 W. 168th Street, New York, NY 1003, USA

M K Sharief, Guy's and St Thomas' Hospital, London, UK

I F Hussain, V J Stecher, M Sweeney, Pfizer Inc., New York, NY, USA This study was funded by Pfizer Inc.

Competing interests: C Fowler has been reimbursed by Pfizer Inc. for speaking at and attending conferences and has also received an 
unrestricted research grant from Pfizer Inc. JR Miller received reimbursement from Pfizer Inc. for attending a symposium. MK Sharief received funds for research from Pfizer Inc. IF Hussain was employed as a research fellow at the National Hospital for Neurology and Neurosurgery, Queen Square, London during the time of the study but is currently an employee of Pfizer Inc. M Sweeney was an employee of Pfizer Inc. at the time this manuscript was submitted. VJ Stecher and $M$ Sweeney are currently employees of Pfizer Inc.

*Current address: CV Therapeutics, 3172 Porter Drive, Palo Alto, CA 94304, USA

\section{REFERENCES}

1 Miller $\mathbf{H}$, Simpson CA, Yeates WK. Bladder dysfunction in multiple sclerosis. BMJ 1965;5445: 1265-9.

2 Vas C. Sexual impotence and some autonomic disturbance in men with multiple sclerosis. Acta Neurol Scand 1969;45:166-82.

3 Betts CD, Jones SJ, Fowler CG, et al. Erectile dysfunction in multiple sclerosis: associated neurological and neurophysiological deficits, and treatment of the condition. Brain 1994;117:1303-10.

4 Mattson D, Petrie M, Srivastava DK, et al. Multiple sclerosis: sexual dysfunction and its response to medications. Arch Neurol 1995;52:862-8.

5 Kirkeby HJ, Poulsen EU, Petersen T, et al. Erectile dysfunction in multiple sclerosis. Neurology 1988:38:1366-71.

6 Minderhoud JM, Leemhuis JG, Kremer J, et al. Sexual disturbances arising from multiple sclerosis. Acta Neurol Scand 1984;70:299-306.

7 Valleroy ML, Kraft GH. Sexual dysfunction in multiple sclerosis. Arch Phys Med Rehabil 1984;65:125-8.

8 Levine AM. Management of multiple sclerosis. How to improve the quality of life. Postgrad Med 1985;77:126-7.

9 Schapiro RT, Langer SL. Symptomatic therapy of multiple sclerosis. Curr Opin Neurol 1994;7:229-33.

10 Lottman PEM, Jongen PJH, Rosier PFWM, et al. Sexual dysfunction in men with multiple sclerosis - a comprehensive pilot-study into etiology. Int J Impot Res 1998; 10:233-7.
11 Goldstein I, Lue TF, Padma-Nathan $\mathrm{H}$, et al. Oral sildenafil in the treatment of erectile dysfunction. N Engl J Med 1998;338:1397-404.

12 Morales A, Gingell C, Collins M, et al. Clinical safety of oral sildenafil citrate (VIAGRA) in the treatment of erectile dysfunction. Int $J$ Impot Res 1998;10:69-74.

13 Giuliano F, Hultling C, El Masry WS, et al. Randomized trial of sildenafil for the treatment of erectile dysfunction in spinal cord injury. Ann Neurol 1999;46:15-21.

14 Derry FA, Dinsmore WW, Fraser M, et al. Efficacy and safety of oral sildenafil (VIAGRA) in men with erectile dysfunction caused by spinal cord injury. Neurology 1998;51:1629-33.

15 Ballard SA, Gingell CJ, Tang K, et al. Effects of sildenafil on the relaxation of human corpus cavernosum tissue in vitro and on the activities of cyclic nucleotide phosphodiesterase isozymes. J Urol 1998;159:2164-71.

16 Boolell M, Allen MJ, Ballard SA, et al. Sildenafil: an orally active type 5 cyclic GMP-specific phosphodiesterase inhibitor for the treatment of penile erectile dysfunction. Int J Impot Res 1996;8:47-52.

17 Kurtzke JF. Rating neurologic impairment in multiple sclerosis: an expanded disability status scale (EDSS). Neurology 1983;33:1444-52.

18 Rosen RC, Cappelleri JC, Gendrano N 3rd. The International Index of Erectile Function (IIEF): a state-of-the-science review. Int J Impot Res 2002; 14:226-44.

19 Fugl-Meyer AR, Lodnert G, Branholm IB, et al. On life satisfaction in male erectile dysfunction. Int J Impot Res 1997;9:141-8.

20 Boulton AJ, Selam JL, Sweeney M, et al. Sildenafil citrate for the treatment of erectile dysfunction in men with type II diabetes mellitus. Diabetologia 2001;44:1296-301.

21 Nurnberg HG, Hensley PL, Gelenberg AJ, et al. Treatment of antidepressantassociated sexual dysfunction with sildenafil: a randomized controlled trial. JAMA 2003;289:56-64

22 Derry F, Hultling C, Seftel AD, et al. Efficacy and safety of sildenafil citrate $\left(V_{i a g r a}{ }^{\circledR}\right)$ in men with erectile dysfunction and spinal cord injury. Urology 2002;60(suppl 2B):49-57.

23 Steers WD. Viagra-after one year. Urology 1999;54:12-7.

24 Rendell MS, Rajfer J, Wicker PA, et al. for the Sildenafil Diabetes Study Group. Sildenafil for treatment of erectile dysfunction in men with diabetes. JAMA 1999;281:421-6. 